Research Article

\title{
Wind Tunnel Test on Local Wind Field around the Bridge Tower of a Truss Girder
}

\author{
Jingyu Zhang, ${ }^{1,2}$ Mingjin Zhang $\mathbb{D}^{1},{ }^{1}$ Bing Huang, ${ }^{3}$ Yongle Li, ${ }^{1}$ Jiaxin Yu, \\ and Fanying Jiang $\mathbb{1}^{1}$ \\ ${ }^{1}$ Department of Bridge Engineering, Southwest Jiaotong University, Chengdu 610031, China \\ ${ }^{2}$ China Railway Major Bridge Reconnaissance \& Design Institute Co., Ltd., Wuhan 430050, China \\ ${ }^{3}$ Sichuan Yakang Expressway Co. Ltd., Chengdu 610041, China \\ Correspondence should be addressed to Mingjin Zhang; zhang108119@163.com
}

Received 3 August 2020; Revised 10 January 2021; Accepted 17 January 2021; Published 29 January 2021

Academic Editor: Tingting Zhang

Copyright ( 2021 Jingyu Zhang et al. This is an open access article distributed under the Creative Commons Attribution License, which permits unrestricted use, distribution, and reproduction in any medium, provided the original work is properly cited.

The aerodynamic performance of vehicles on a bridge deck depends on the local wind field, especially in a region near a bridge tower. This study was carried out on a large-scale (1:20.4) truss girder, and wind tunnel tests were performed to determine how the wind fields were affected by the bridge tower in the presence of different wind barriers. The wind barrier parameters significantly affect the wind field. Wind barriers should be sufficiently high to provide a wide protection range and have relatively small porosities to reduce the wind speed. The opening form of the wind barrier should also be considered, where a circular-holed form reduces the wind speed and turbulence more than a horizontal-slatted form. The wind field is affected by structures and bridge towers on the deck. A turning point in the wind speed occurs at a measurement point near the bridge tower, and this point gradually moves upward towards lanes on the leeward side of the bridge. The equivalent wind speed is significantly reduced over a four-meter height range because of shadowing from the bridge tower and the wind barrier.

\section{Introduction}

Many long-span bridges with strong spanning capacities have been built to cross canyons, rivers, lakes, etc. Many of these bridges, such as the Hardanger Bridge [1] and the Aizhai Bridge [2], span more than $1000 \mathrm{~m}$. The wind speed in narrow regions, such as canyons, can be very high $[3,4]$, and vehicle safety may be threatened by these complex wind fields $[5,6]$. Studies of wind fields on bridge decks can serve as references for bridge design to ensure the running safety of vehicles.

The wind field on a bridge deck can affect the aerodynamics and wind-induced response of vehicles. The wind pressure distribution was investigated using a single-box bridge model without nearby structures, and the wind pressure was found to be relatively high at the upstream side of the upper surface (the bridge deck) [7]. Kozmar et al. [8] performed wind tunnel tests to study the sheltering effect of wind barriers on a viaduct; in the absence of a barrier, the relatively high wind speed on a bridge can induce instabilities in high-sided vehicles. After installing a barrier, both the wind speed and instability of high-sided vehicles decrease. The following results were obtained from investigating the effect of wind barrier parameters on windresistance performance; increasing the barrier porosity increases the wind speed behind the barrier, especially downstream of the barrier [9]; an optimal porosity range for barriers has been reported in many studies [10-12]; the barrier height can affect the wind distribution behind the barriers [13]; and increasing the barrier height reduces the wind speed near the barriers but increases the wind speed at the trailing edge of the bridge [9]. A numerical method was used to investigate how the inclination angle of the barrier bars modified the shelter effect, considering a total of five bars with different angles [14,15]. Su et al. [16] performed an in-depth study on full-scale wind barriers; the flow field around the barriers was determined by performing wind tunnel tests, including tests on the aerodynamic forces 
exerted on the barrier, and the wind profiles in the upstream and downstream areas of the barriers were found.

A sudden change in the wind profiles can affect the wind force acting on vehicles, which may result in accidents [17]. Argemtini et al. [18] performed wind tunnel tests to study vehicle aerodynamics under different conditions in the vicinity of a single tower; the wind-induced stability of the vehicle is affected by the shielding in the wake of the tower as the vehicle passes by. Charuvisit et al. [19] studied the wind distribution at a specific height above a bridge deck behind different towers with wind barriers and found that the shape and size of the tower can affect the wind field behind the tower. Many researchers have investigated the sheltering effect of bridge towers mainly for vehicles [20-22].

In summary, previous studies have mainly determined the vehicle responses and pressure distribution under cross winds. In this study, the wind field was determined at multiple heights above a bridge deck under different conditions. Large-scale wind tunnel tests (model scale: 1:20.4) were carried out. The wind fields were determined at different heights above the bridge deck in the presence of wind barriers with different barrier heights, porosities, and opening forms. The research background and the configuration of the wind tunnel tests are presented in Section 2. In Section 3, the results of the study are presented, including the contours of the wind speed above the bridge deck, the wind profiles at different longitudinal positions, and the equivalent wind speeds within a $4 \mathrm{~m}$ range under different conditions.

\section{Background and Experimental Setup}

The Dadu River Xingkang Bridge is located on the expressway between Ya'an and Kangding and is the first longspan suspension bridge along the Sichuan-Tibet Highway. This bridge is known as the Sichuan-Tibet First Bridge. The bridge span is $1100 \mathrm{~m}$, and the altitude of the bridge deck is $1608 \mathrm{~m}$. A photograph of the bridge is shown in Figure 1. The local topography at the bridge site is shown in Figure 2.

2.1. Description of Bridge Site. The bridge is located inland in western China in a typical deep-cut and dry, hot canyon $[23,24]$. The altitudes of the mountains on both sides of the canyon exceed $5000 \mathrm{~m}$, and the height difference between the mountain peak and the valley bottom exceeds $3500 \mathrm{~m}$. The mountains on the both sides of the canyon are covered with snow all year round, and temperature differences between the mountain top and the valley bottom can create strong winds at the bridge site. There is a southwest-northeast trend ridge on the east side of the bridge. The average altitude of the ridge of approximately $2000 \mathrm{~m}$ far exceeds that of the bridge deck. Consequently, an automatic weather station was built on the west side, below the bridge deck, to perform a preliminary investigation of the wind field at the bridge site. The automatic weather station is approximately $500 \mathrm{~m}$ away from the midpoint of the bridge and approximately $78 \mathrm{~m}$ from the bridge deck. The maximum 10-minute average wind speed is more than $29.6 \mathrm{~m} / \mathrm{s}$, based on historical

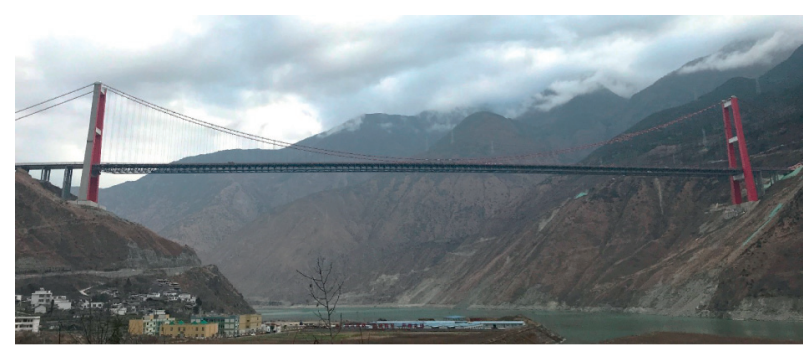

FIgURE 1: View of the Dadu river Xingkang bridge.

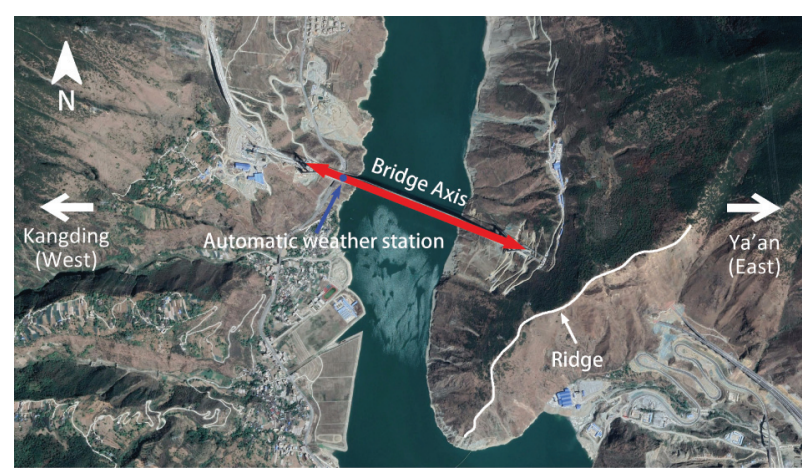

Figure 2: Terrain at bridge site (captured from Google Earth).

wind data for the bridge site [25]. The maximum wind speed has reached $44.5 \mathrm{~m} / \mathrm{s}$, based on the instantaneous maximum wind speed over 3 seconds, which is comparable to the speed of a hurricane.

2.2. Wind Tunnel Tests. All the tests were carried out in a XNJD-3 wind tunnel at Southwest Jiaotong University; the dimensions of the closed-circuit down-blowing type tunnel are $22.5 \mathrm{~m}$ (width) $\times 4.5 \mathrm{~m}$ (height) $\times 36.0 \mathrm{~m}$ (length). The wind speed range is $0.5 \sim 16.5 \mathrm{~m} / \mathrm{s}$. The scale ratio of the bridge section model was set to 1:20.4. A sketch of the model, including the dimensions, is shown in Figure 3, and Figure 4 shows the model placed in the wind tunnel. The scaled model is $3460 \mathrm{~mm}$ long, $406.9 \mathrm{~mm}$ high, and $1323.5 \mathrm{~mm}$ wide. The section form is a truss type, the bridge deck is designed on the top of the bridge, and there is a vertical stabilizer in the central deck. A Cobra probe with a speed accuracy of $0.3 \mathrm{~m} / \mathrm{s}$ was used to measure the wind speed above the bridge deck at a sampling rate of $1000 \mathrm{~Hz}$.

Wind barriers are used in transportation structures as an effective means of wind protection. A total of 4 different wind barriers were used in the wind tunnel tests. The effects of the type of the opening form, height, and porosity of the wind barrier on the local wind field were investigated (see Figure 5). The parameters of different wind barriers are listed in Table 1. WB-1 was provided by the bridge design and selected as the control group. A bridge tower with a scaled size of approximately $520 \mathrm{~mm}(\mathrm{D}) \times 380 \mathrm{~mm}(\mathrm{~W})$ was added to the model to study the influence of a bridge tower on the wind field above the bridge deck. The arrangement of the measurement points is shown in Figure 6, where the tower length $D=520 \mathrm{~mm}$ in the test. The wind profiles above the 


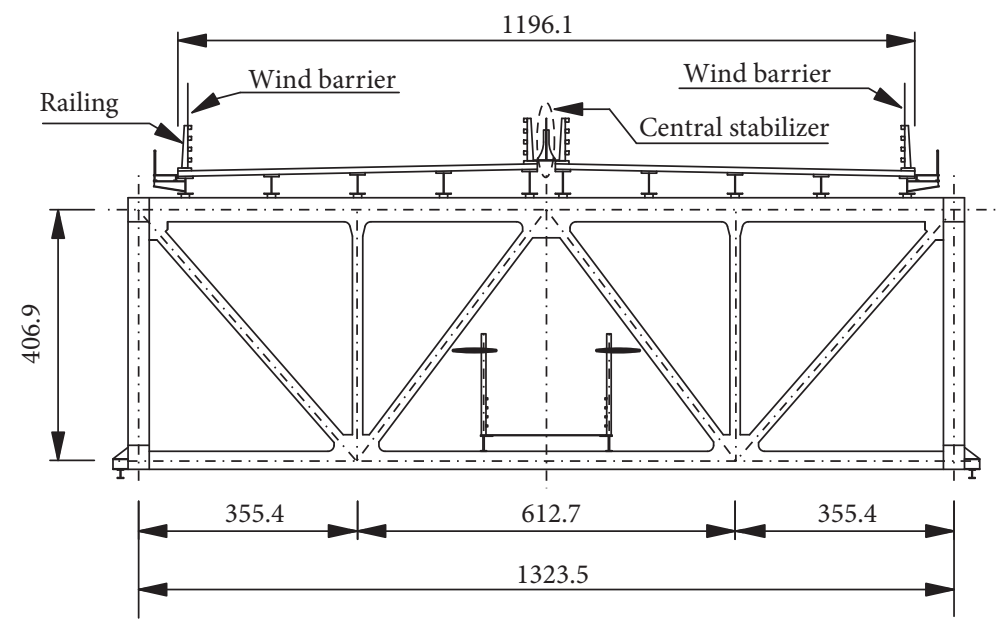

FIgURE 3: Scaled model of the bridge section (units: $\mathrm{mm}$ ).

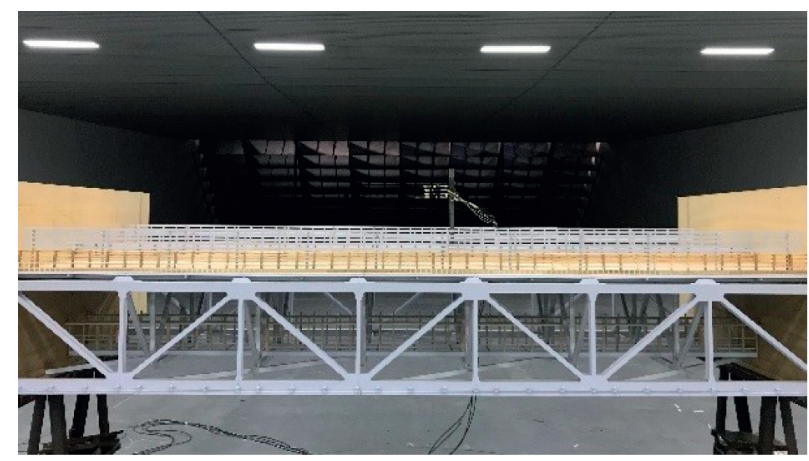

Figure 4: Model placed in the wind tunnel.

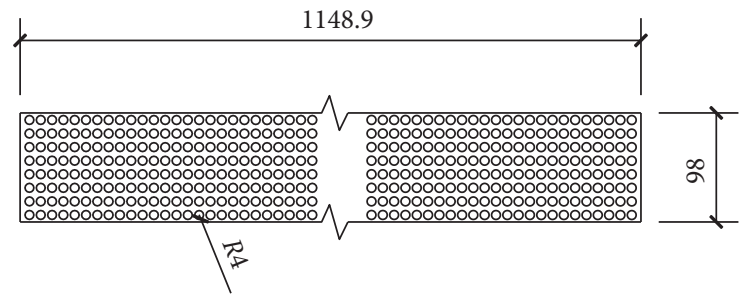

(a)

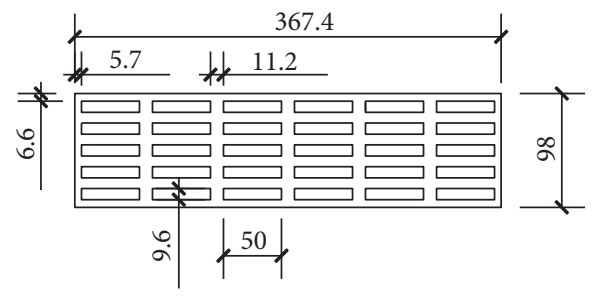

(b)

Figure 5: Sketches of wind barriers used in wind tunnel tests (units: mm): (a) circular-holed barrier; (b) horizontal-slotted barrier.

TABLE 1: Parameters of different wind barriers at full scale.

\begin{tabular}{lccc}
\hline No. & Opening form & Full-scale height $(\mathrm{m})$ & Porosity $(\%)$ \\
\hline WB-1 & & 2 & 40 \\
WB-2 & Horizontal-slotted & 2 & 50 \\
WB-3 & & 1.2 & 40 \\
\hline WB-4 & Circular-holed & 2 & 40 \\
\hline
\end{tabular}




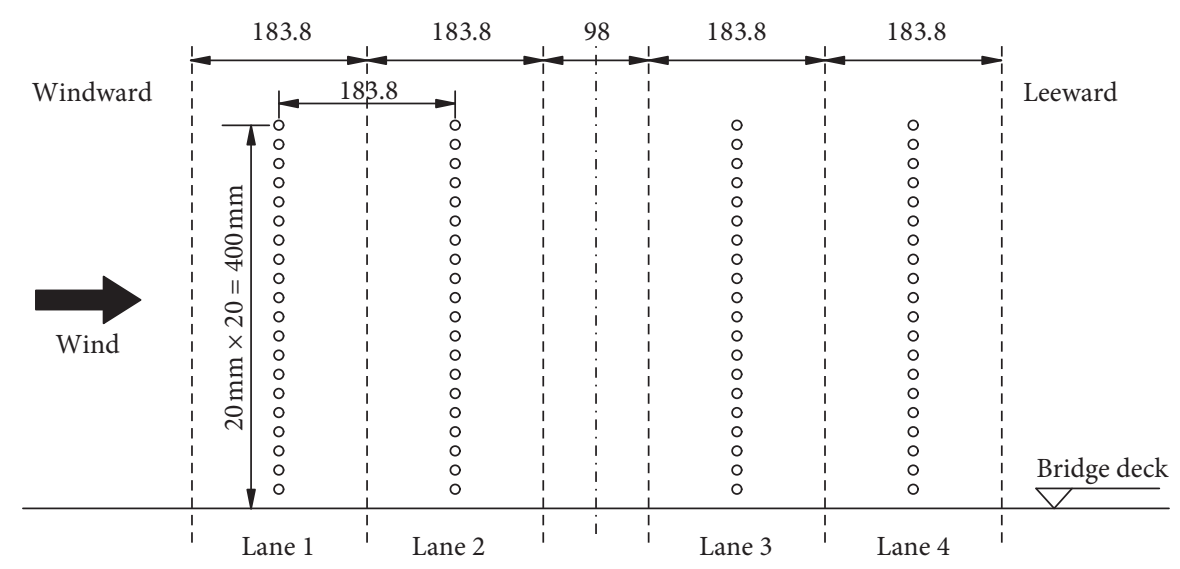

(a)

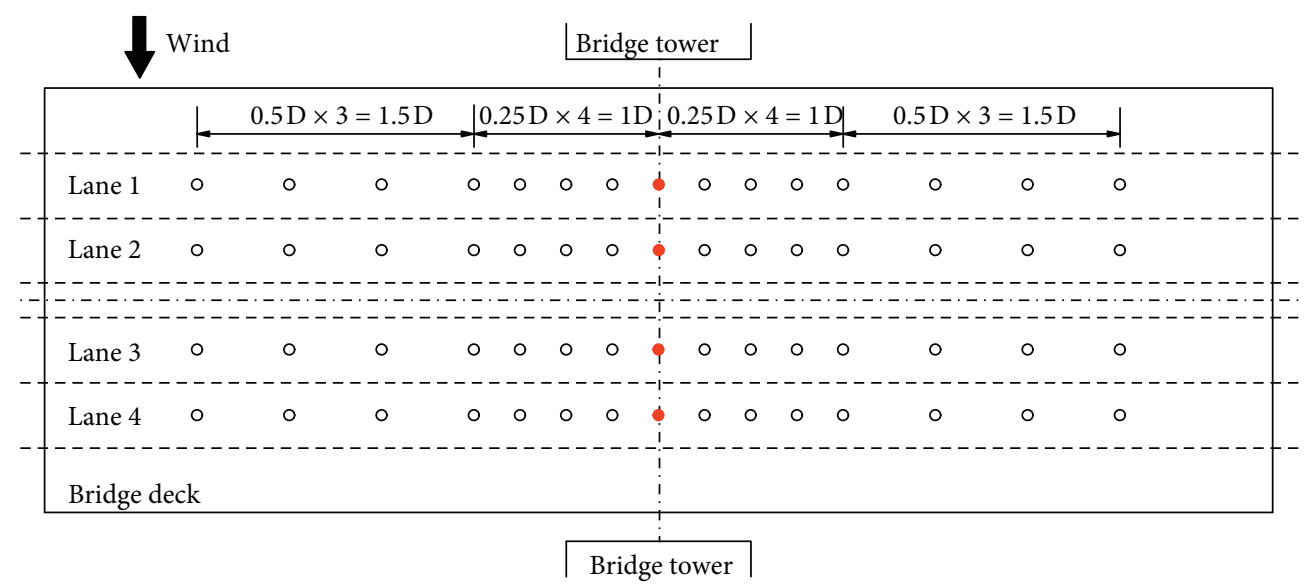

(b)

FIgURE 6: Locations of wind speed measurement points in tests (units: mm): (a) elevation view; (b) top view.

four lanes of the deck were determined. A total of 20 measurement points with a $20 \mathrm{~mm}$ spacing (corresponding to $0.408 \mathrm{~m}$ at full scale) in the vertical direction were used for each lane, and a full-scale height range of 0 to $8.16 \mathrm{~m}$ was investigated. In the absence of the bridge tower, the wind speed profile was only determined for one section, as indicated by the red points shown in Figure 6(b).

\section{Results and Discussion}

3.1. Wind Speed Contours for Different Heights above Deck. The large pylons typically used in long-span bridges produce a discontinuity in the wind field above the bridge deck $[19,26]$. Bridge towers were installed at the windward and leeward sides of the deck to investigate the effect of bridge towers on the wind field, where the scaled tower dimensions were $520 \mathrm{~mm}(\mathrm{D}) \times 380 \mathrm{~mm}(\mathrm{~W})$. Four different wind barriers with different porosities, opening forms, and heights were also added to the deck. WB-1 was provided by the bridge design company and used as the control in the tests. The test range of the wind field was five times the tower width, i.e., 5D [27]. The wind speed $U$ in this section is normalized by the free-stream speed $U_{0}(10 \mathrm{~m} / \mathrm{s})$. Figure $6(\mathrm{a})$ shows the test results as contours, each of which includes 20 subfigures showing the wind field contour for each height above the deck.

Figure 7 shows the wind field contours in the absence of barriers. The most prominent feature of the air flow behind the bridge tower is the sudden change in the wind speed caused by the tower; the wind speed is clearly reduced behind the tower and then increases rapidly away from the tower. When the Cobra probe is placed behind the railings, the wind speed distribution is mainly dominated by the structures near the bridge deck. As the Cobra probe is moved upward, the shelter range of the tower at the windward side gradually increases, whereas that at the leeward side gradually decreases. This result is obtained because of the gradual diminishing influence of structures, such as railings, on the bridge deck. The influence of these structures on the wind field gradually becomes less dominant, where the influence range is approximately $260 \mathrm{~mm}$. The wind speed is dominated by the bridge tower at heights above the deck larger than $280 \mathrm{~mm}$, and the bridge tower has a noticeable shear layer effect at large wind speed gradient. The installation of WB-1 wind barriers (see Figure 8) significantly changes the wind field above the bridge deck. At lower heights above the bridge deck, the wind speed reaches a minimum behind the wind barrier and then increases. The wind barrier reduces 


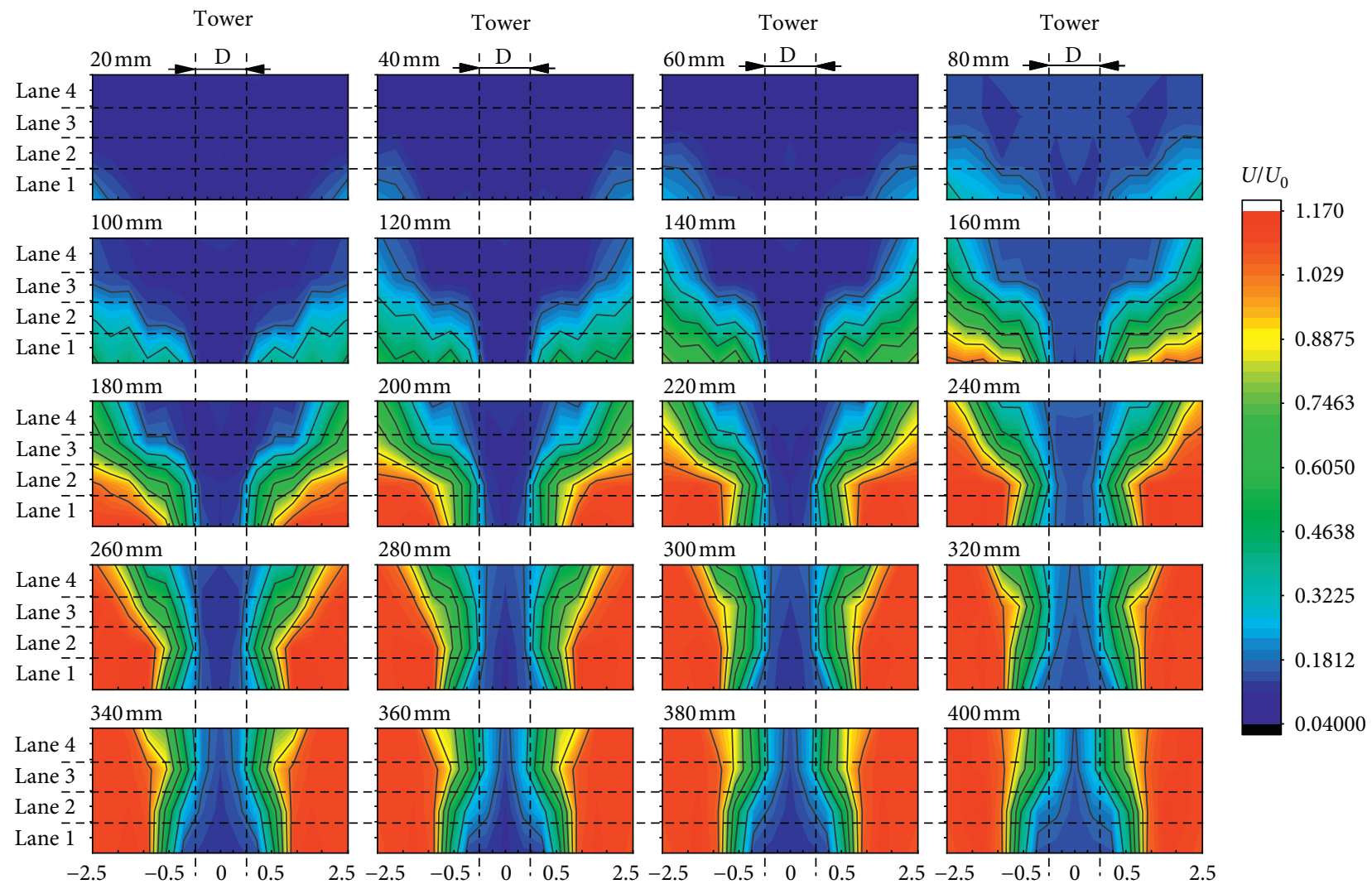

FIgURE 7: Contours of wind field on the bridge deck without wind barriers.

the gradient of the wind speed, weakening the mutation effect of the bridge tower on the wind speed. The wind barriers reduce the maximum normalized wind speed from 1.16 to 0.65 for wind fields at positions less than $200 \mathrm{~mm}$ above the deck. The maximum normalized wind speed occurs at positions below $80 \mathrm{~mm}$ above the deck, which is different from the result obtained in the absence of a wind barrier. As most vehicles are less than $4 \mathrm{~m}$ high (corresponding to approximately $200 \mathrm{~mm}$ in the tests), wind barriers can significantly reduce cross winds acting on road vehicles, effectively reducing the risk of vehicle rollover [28].

3.1.1. Effects of Porosity. High-porosity wind barriers were used in the tests to investigate the effect of the wind barrier porosity on the wind field. Figure 9 clearly shows that the use of low-porosity barriers decreases the wind speed within the test height range. Changing the porosity affects the wind field less than $240 \mathrm{~mm}$ above the deck, especially at the windward side. The porosity of the railings is approximately 63\%. As the railings have a lower porosity than WB-2, less flow passes through the railing than through the barriers. Thus, the wind speed is low below the railing height and increases behind the high-porosity barriers. The high-porosity barriers even increase the wind speed at the leeward side. Thus, the wind speed is dominated by the railings and wind barriers closer to the deck. The increase in the wind speed gradient has a larger mutation effect further above the deck. Generally, the range of protection also decreases as the porosity increases. The wind speed increases between $100 \mathrm{~mm}$ and $240 \mathrm{~mm}$ above the deck, and the crosswind will exert a large sideways force on vehicles, which may increase the risk of side slip and rollover, especially for high-sided vehicles. Thus, the installation of low-porosity barriers is recommended for bridges in regions of high wind speeds that are traversed by a large number of high-sided vehicles.

3.1.2. Effects of Wind Barrier Height. The wind barrier height is one of most important parameters in wind barrier design. A second type of wind barrier with a full-scale height of $1.2 \mathrm{~m}$ was used in the tests to investigate the effect of the wind barrier height on the wind-resistance performance. The results at different heights above the deck are shown in Figure 10.

Figure 10 shows a similar wind speed distribution obtained using WB-3 as with WB-1. Placing a Cobra probe behind the railings results in a similar wind speed distribution law as for the WB-1 case, except that the wind magnitude is smaller. As the height of the Cobra probe above the deck increases, the wind speed behind the wind barriers decreases, but the distribution law remains the same. This result is obtained because lower barriers create less blockage above the deck, such that more flow passes over the wind barriers, decreasing the wind speeds behind both the railings and the barriers. When the Cobra probe is moved out of the barrier region, similar wind fields are found as shown in Figure 8 at a height of $340 \mathrm{~mm}$ above the deck and in 


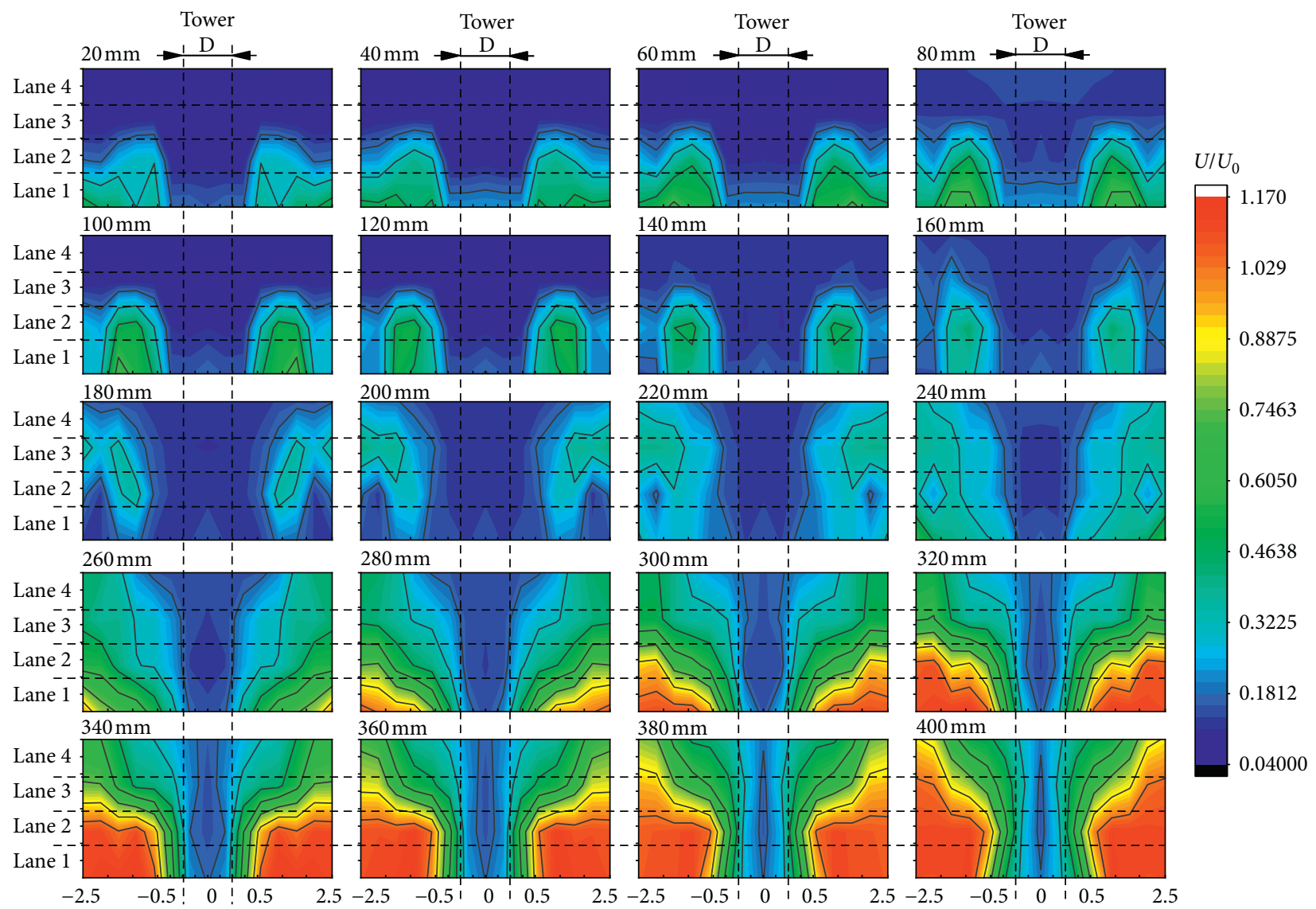

FIgURE 8: Contours of wind field above the bridge deck in the presence of WB-1 barriers.

Figure 10 at a height of $280 \mathrm{~mm}$ above the deck. At a low barrier height, the wind-resistance performance and the range of the protection region decrease significantly, and the wind speed at the windward side approaches the incoming wind speed earlier. Generally, the range of protection provided by WB-3 is approximately $160 \mathrm{~mm}$ above the deck, which is considerably lower than the value of $240 \mathrm{~mm}$ provided by WB-1. This result can be explained using the aforementioned reasoning; lower barriers allow more flow to pass over the barriers and increase the wind speed. As a higher region of protection $(320 \mathrm{~mm} \sim 400 \mathrm{~mm})$ is provided by a lower barrier, the higher wind speed gradient creates large mutation effects, which is similar to the results obtained in the absence of barriers.

\subsubsection{Effects of Opening Forms. Circular-holed wind barriers} were used in the tests to investigate the effect of the opening form of the wind barriers on the wind field. Figure 11 shows that the wind fields at different heights above the deck are similar to those obtained in the presence of WB-1. The wind speed increases over the protection range of the railings near the bridge deck, where the fluctuations in the wind speed are larger at the windward side. The wind speed decreases slightly over the region near the wind barriers. The wind speed drops dramatically at the measurement points behind the barriers and reaches a minimum near the top of the wind barrier. When the Cobra is placed higher above the deck (but not above $240 \mathrm{~mm}$ ), the wind speed remains low. At heights between $260 \mathrm{~mm}$ and $300 \mathrm{~mm}$ above the deck, the wind speed above lane 2 remains unchanged from $0.5 \mathrm{D}$ to $2 \mathrm{D}$ and $-0.5 \mathrm{D}$ to $-2 \mathrm{D}$, and the wind speed only changes above lane 1. At heights greater than $380 \mathrm{~mm}$ above the deck, there is little change in the distribution law for the wind speed obtained in the presence of WB-1 and WB-4. The change in the wind speed gradients obtained using the two opening forms is small. The difference in the wind speed distribution at less than $260 \mathrm{~mm}$ above the deck obtained using the two forms can be explained in terms of the wider and more uniform distribution of the circular holes than the horizontal slots, which has a higher blockage effect on the airflow. Thus, the opening form can change the wind-resistance characteristics of a wind barrier. Circular-holed barriers reduce the wind speed and increase the protection range compared with horizontal-slotted barriers. Combined with the porosity and height, we can see that changing the porosity and height of the wind barrier is more effective than changing the opening form of the wind barrier.

3.2. Wind Profiles at Different Longitudinal Positions. The contours of the wind field at different heights above the bridge deck were presented in the previous section. The wind profiles at different longitudinal positions along the bridge 


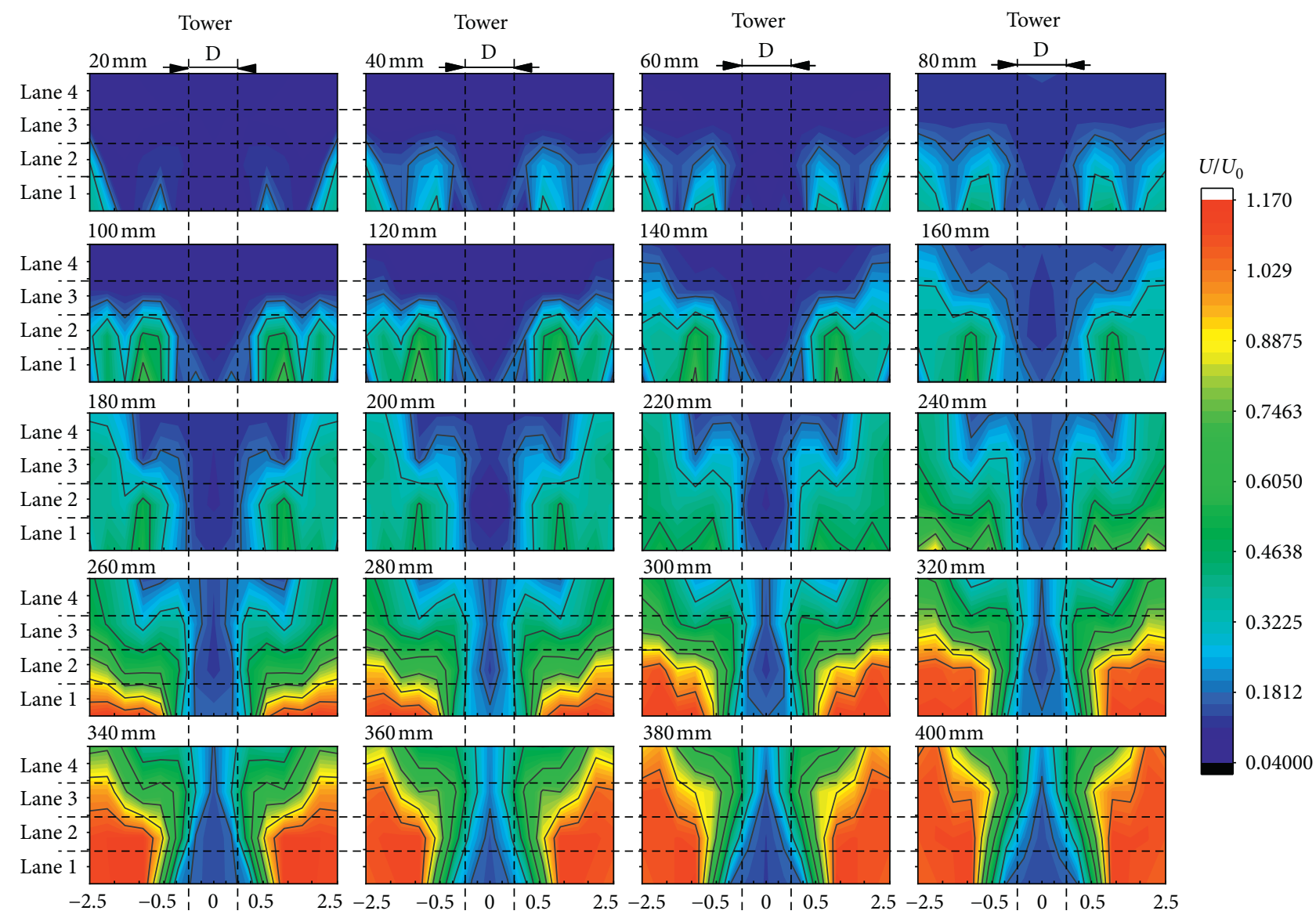

FIgURE 9: Contours of wind field above the bridge deck in the presence of WB-2 barriers.

deck are analyzed in this section. The range of influence of the bridge tower is between $0.5 \mathrm{D}$ and $1.5 \mathrm{D}$. The wind profiles at $0.5 \mathrm{D}, 0.75 \mathrm{D}, 1 \mathrm{D}, 1.5 \mathrm{D}$, and $2 \mathrm{D}$ are plotted in Figure 12. Near the bridge tower and in the absence of wind barriers, the turning point in the wind speed moves upward from the windward side to the leeward side. With increasing distance from the bridge tower, the turning point disappears and is replaced by a wind speed stabilization point. The stabilization point also moves upward from the windward side to the leeward side. In the presence of wind barriers, the turning point in the wind speed near the tower moves upward, and the wind speed remains low close to the deck. The results obtained at measurement points at different longitudinal positions show that the bridge tower and the wind barrier have a strong influence on the wind profile above lane 1 , compared with a relatively weak influence on the wind profile above lane 2 . The wind speed at the leeward side remains low close to the deck because of shielding effect by the central stabilizer. In addition, wind barriers with different parameters provide different wind protection effects. The wind speed behind the low-porosity wind barriers is considerably lower than that behind the high-porosity barriers. However, the difference between the porosities of the wind barrier and the railing causes the wind speed behind the railing to increase in the presence of low-porosity wind barriers. A similar change law for the wind speed with the barrier height is obtained as for the porosity cases, that is, the higher the wind barrier is, the stronger the wind protection effect is. The horizontal-slotted opening exhibits superior wind proofing performance to the circular-holed opening.

3.3. Equivalent Wind Speed. The influence of the bypass flow on the incoming flow is reflected by introducing an equivalent wind speed, which is obtained by transforming the normalized wind profile to a uniform profile. The principle of equivalent lateral forces is used to derive the following expression for the equivalent wind speed [29]:

$$
U_{e q S}=\sqrt{\frac{1}{Z_{r}} \int_{0}^{Z_{r}} U^{2}(z) \mathrm{d} z},
$$




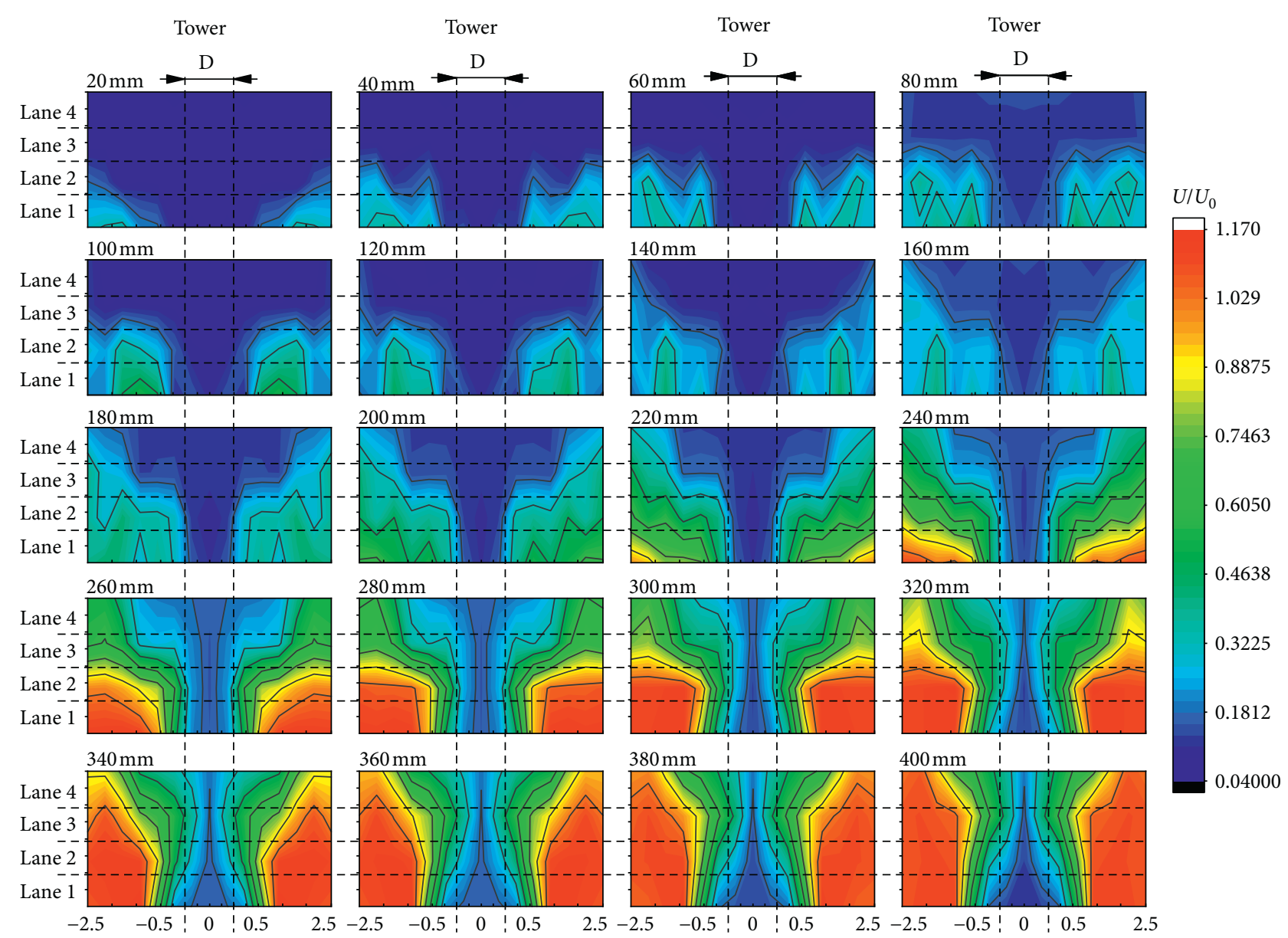

FIGURE 10: Contours of wind field above the bridge deck in the presence of WB-3 barriers.

where $U_{e q S}$ is the equivalent wind speed, $U(z)$ is the normalized wind speed at a height $z$ above the bridge deck, and $Z_{r}$ is the corresponding height above the deck of the equivalent wind speed. Considering the height of a highsided vehicle, $Z_{r}$ is set as $4 \mathrm{~m}$ [30].

Table 2 shows the equivalent normalized wind speeds under various conditions calculated using equation (1). The wind speed at the windward side is high, whereas the wind speed on the leeward side is always low because of the presence of the central stabilizer. Installing a wind barrier decreases the equivalent wind speed at all measurement positions. The equivalent wind speed tends to stabilize beyond $1 \mathrm{D}$, which explains why the significant range of influence of the bridge tower on the windward side is approximately 0.5 times the bridge tower width. Further away from the bridge tower, the wind barrier makes the wind speed in different lanes more uniform within $4 \mathrm{~m}$ above the deck and reduces the magnitude of the sudden change in the wind speed in the longitudinal direction, which is conducive to driving safety. The height and the porosity of the wind barrier have a significantly stronger effect on the wind field than the opening type. 


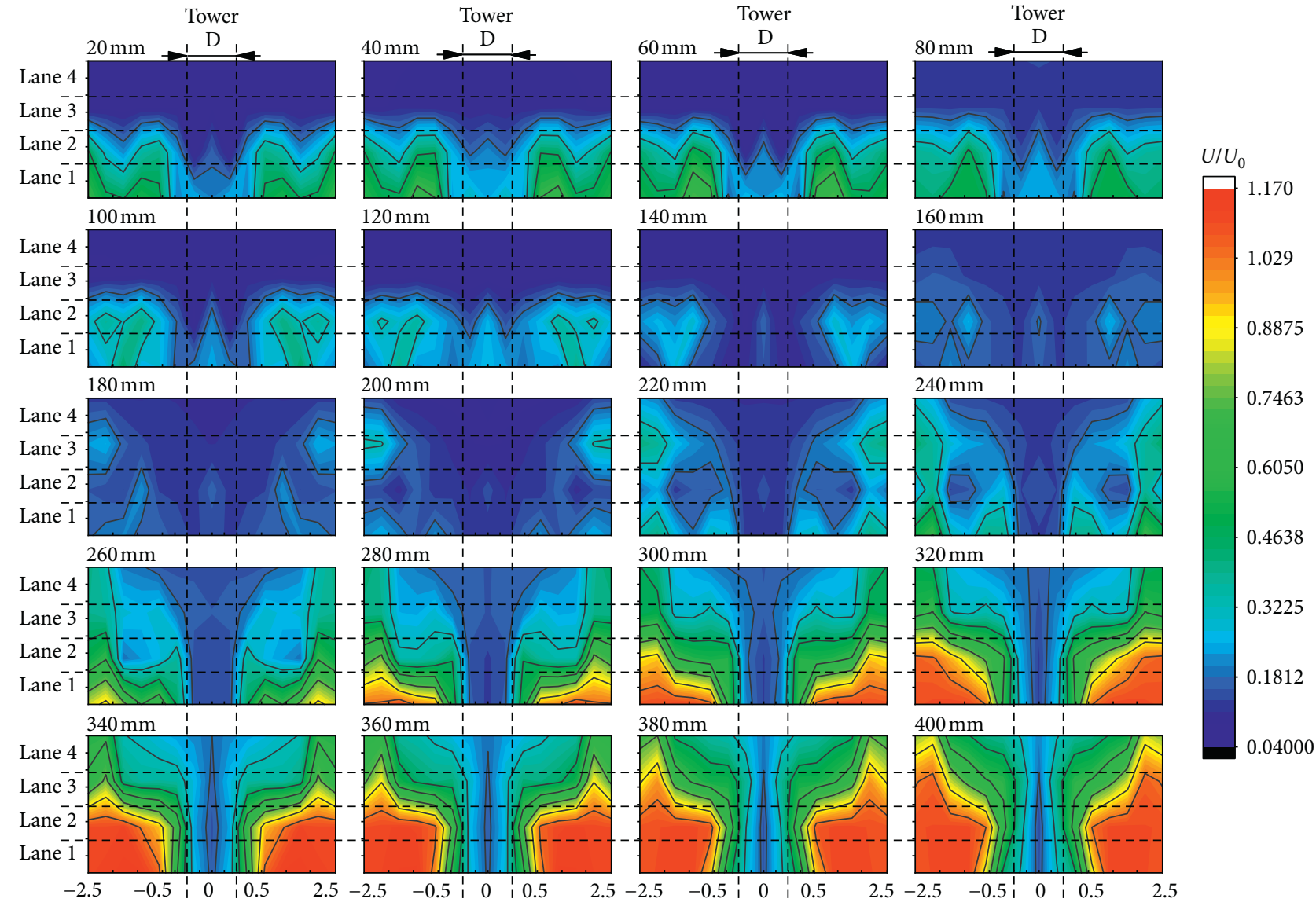

Figure 11: Contours of wind field above the bridge deck in the presence of WB-4 barriers.

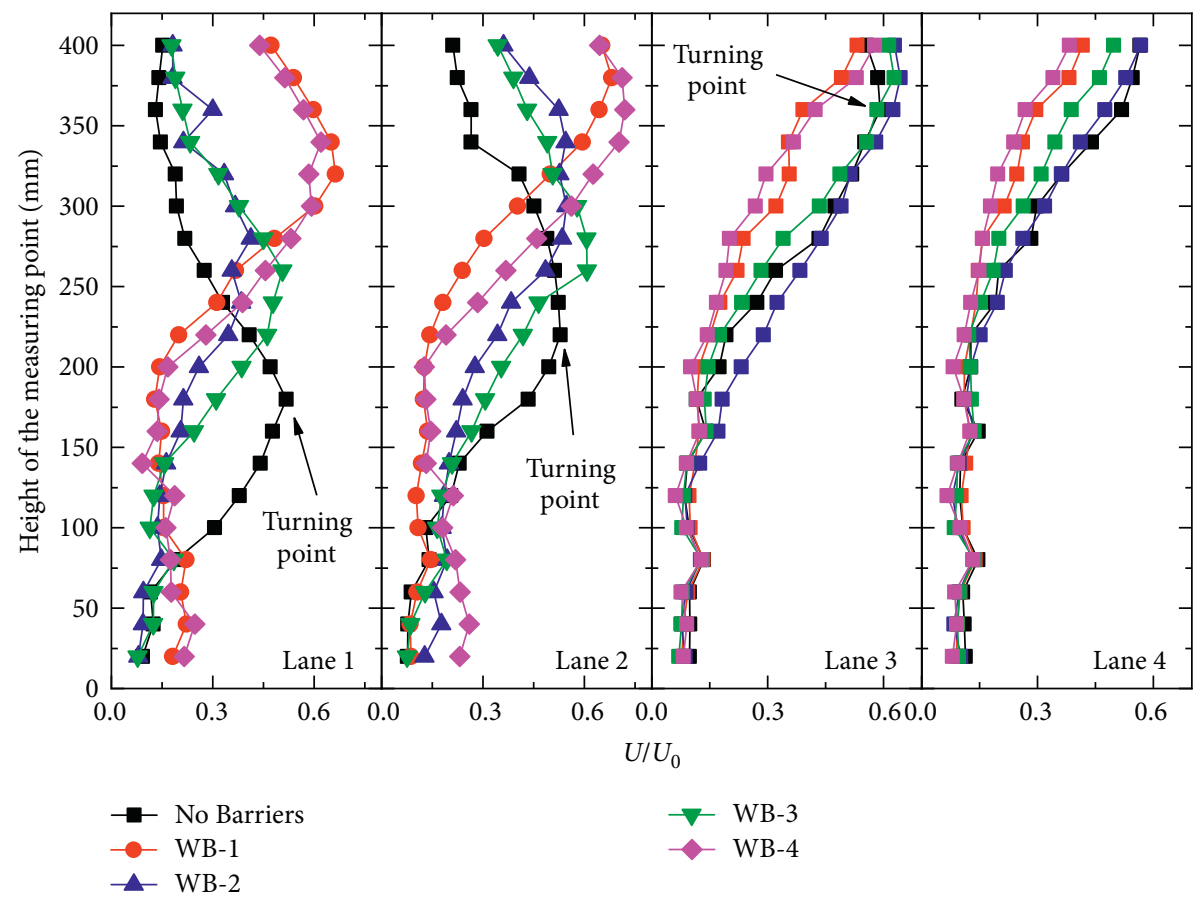

(a)

Figure 12: Continued. 


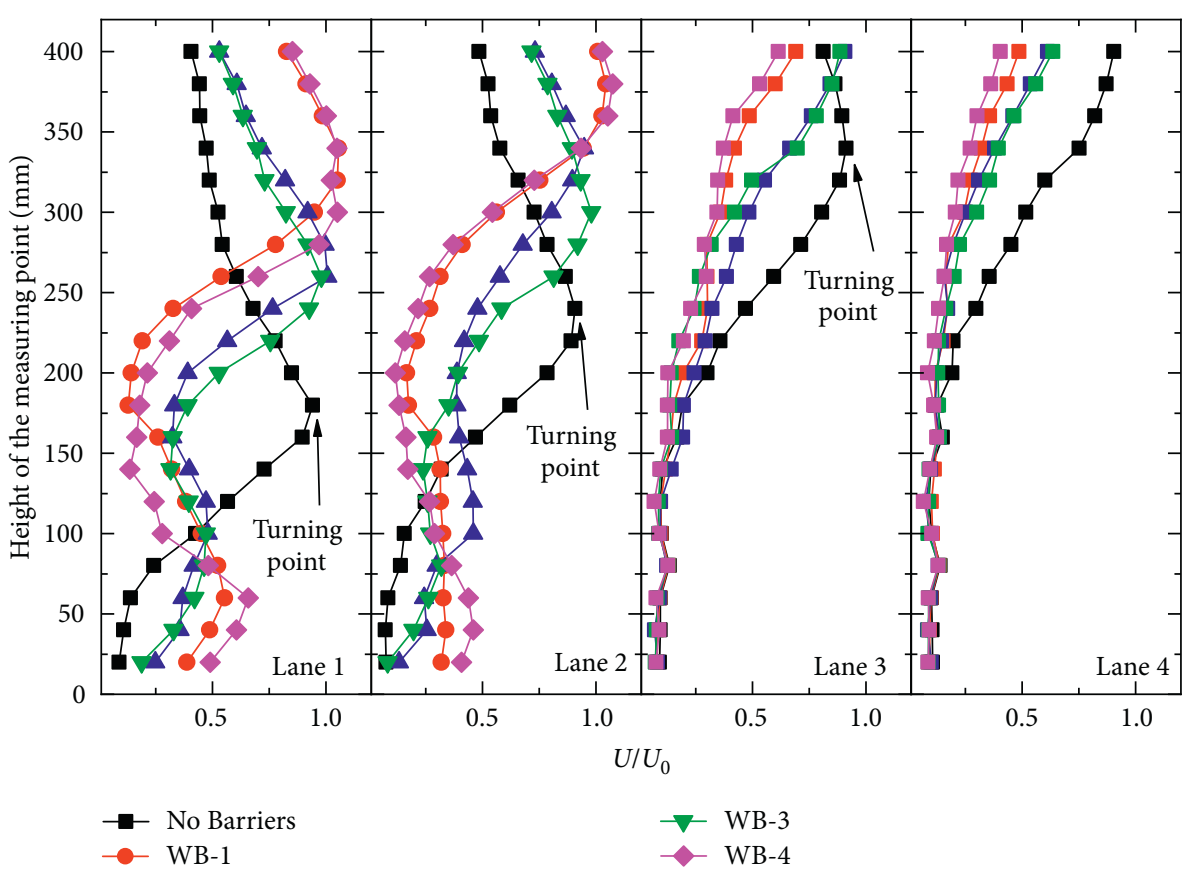

(b)

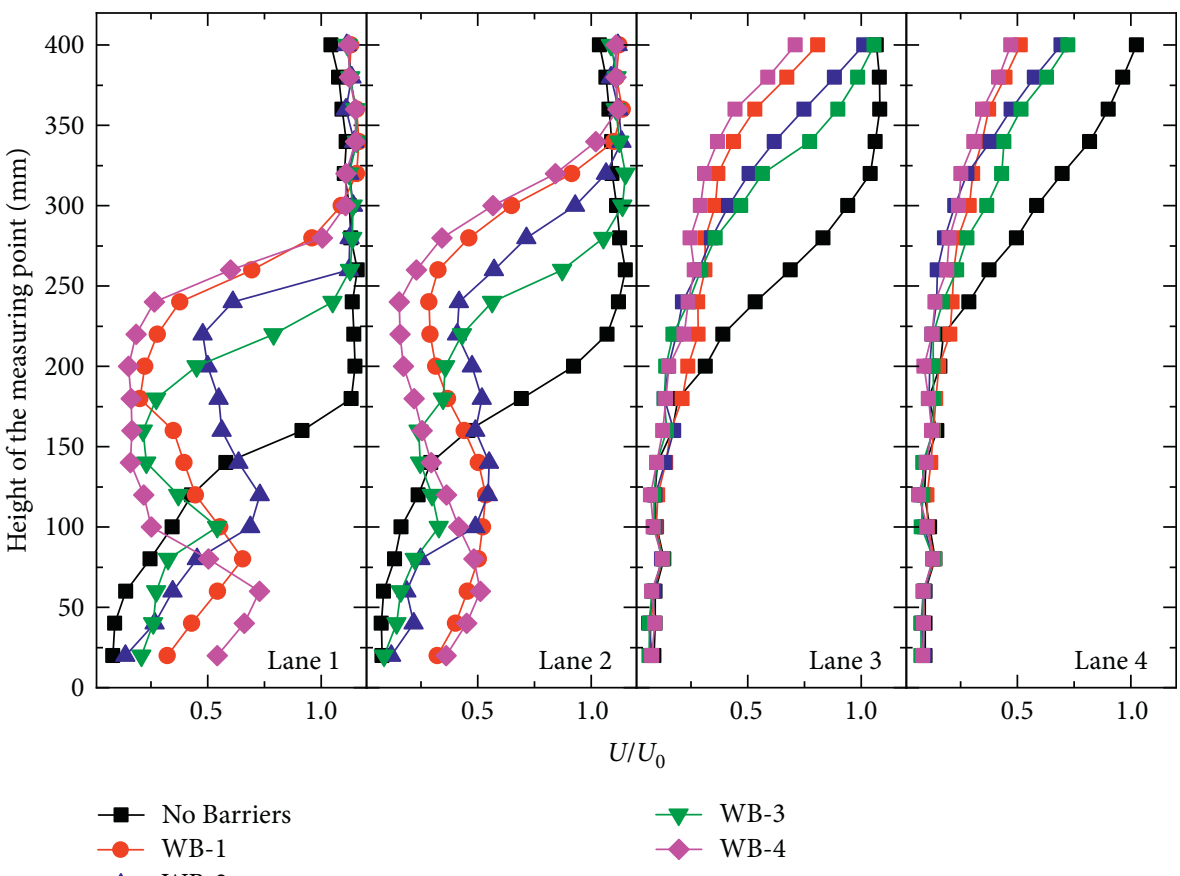

(c)

FIgURE 12: Continued. 


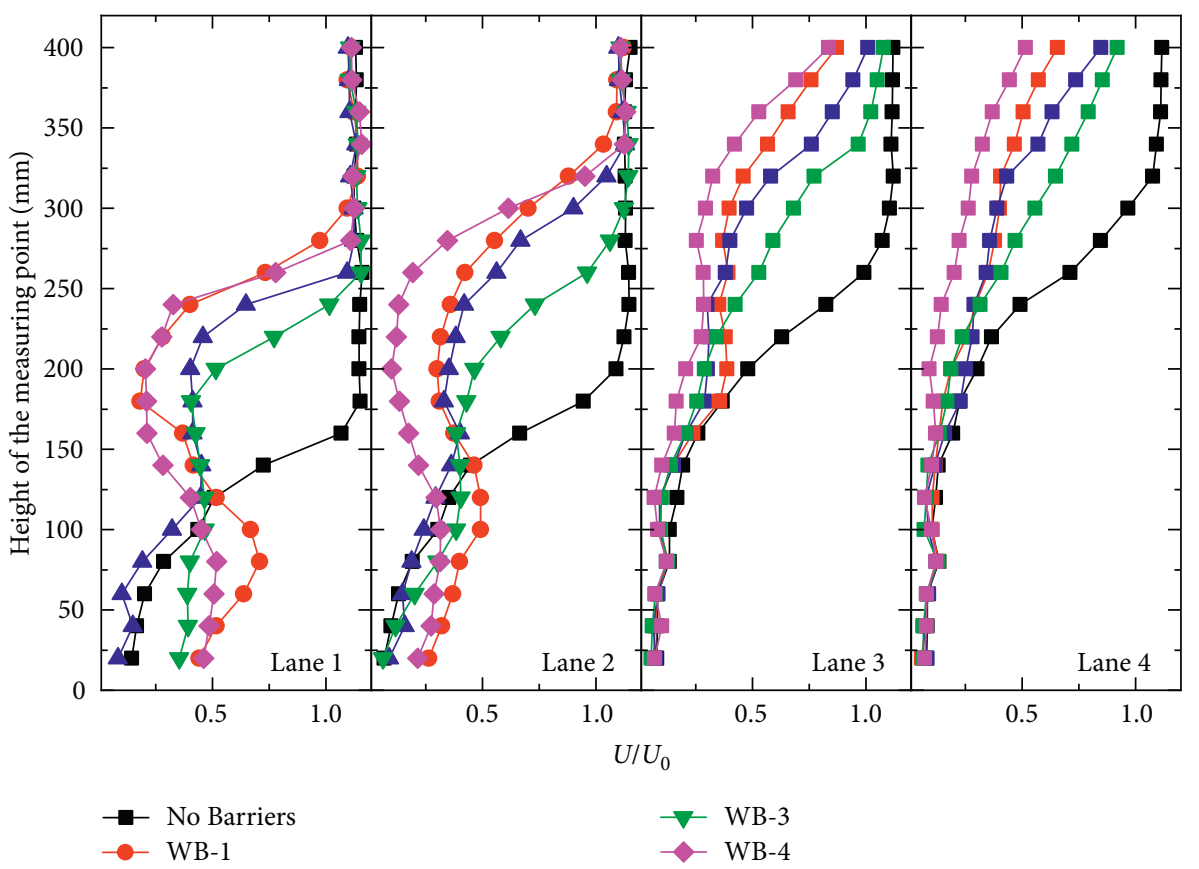

(d)

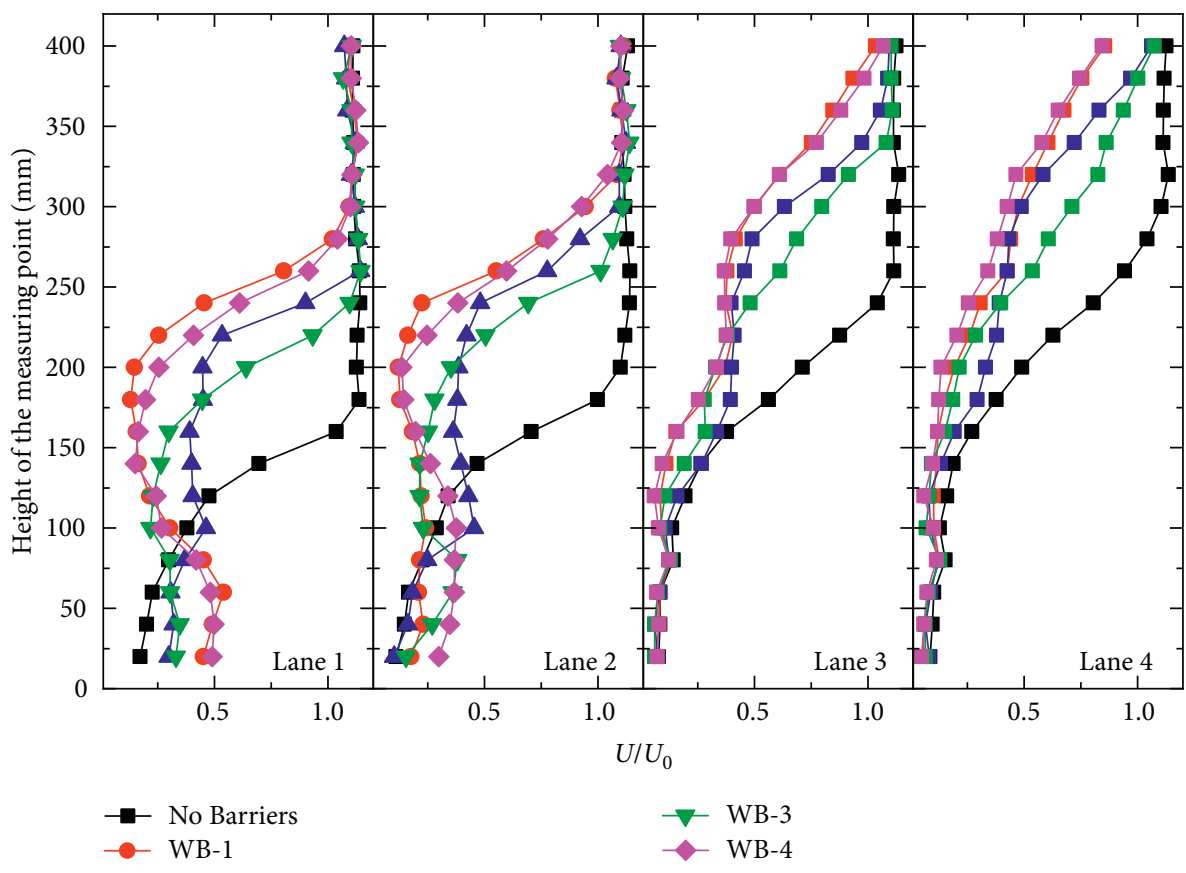

(e)

FigURE 12: Wind profiles above the bridge deck at different longitudinal positions: wind profiles at (a) $0.5 \mathrm{D},(\mathrm{b}) 0.75 \mathrm{D}$, (c) $1 \mathrm{D}$, (d) $1.5 \mathrm{D}$, and (e) $2 \mathrm{D}$. 
TABLE 2: Normalized wind speed under different conditions.

\begin{tabular}{|c|c|c|c|c|c|c|}
\hline \multirow{2}{*}{ Position } & \multirow{2}{*}{ Lane no. } & \multicolumn{5}{|c|}{ Wind barrier type } \\
\hline & & No barriers & WB-1 & WB-2 & WB-3 & WB-4 \\
\hline \multirow{4}{*}{$0.5 \mathrm{D}$} & Lane 1 & 0.35 & 0.17 & 0.16 & 0.21 & 0.17 \\
\hline & Lane 2 & 0.26 & 0.12 & 0.20 & 0.21 & 0.19 \\
\hline & Lane 3 & 0.12 & 0.11 & 0.14 & 0.11 & 0.10 \\
\hline & Lane 4 & 0.12 & 0.11 & 0.11 & 0.11 & 0.10 \\
\hline \multirow{4}{*}{$0.75 \mathrm{D}$} & Lane 1 & 0.60 & 0.39 & 0.38 & 0.39 & 0.39 \\
\hline & Lane 2 & 0.38 & 0.30 & 0.36 & 0.27 & 0.31 \\
\hline & Lane 3 & 0.15 & 0.12 & 0.14 & 0.11 & 0.10 \\
\hline & Lane 4 & 0.12 & 0.11 & 0.11 & 0.11 & 0.10 \\
\hline \multirow{4}{*}{$1 \mathrm{D}$} & Lane 1 & 0.65 & 0.43 & 0.52 & 0.33 & 0.42 \\
\hline & Lane 2 & 0.42 & 0.44 & 0.42 & 0.26 & 0.37 \\
\hline & Lane 3 & 0.15 & 0.14 & 0.12 & 0.11 & 0.11 \\
\hline & Lane 4 & 0.12 & 0.12 & 0.10 & 0.10 & 0.10 \\
\hline \multirow{4}{*}{$1.5 \mathrm{D}$} & Lane 1 & 0.70 & 0.50 & 0.33 & 0.43 & 0.39 \\
\hline & Lane 2 & 0.55 & 0.39 & 0.28 & 0.34 & 0.24 \\
\hline & Lane 3 & 0.24 & 0.20 & 0.17 & 0.16 & 0.12 \\
\hline & Lane 4 & 0.16 & 0.12 & 0.14 & 0.11 & 0.10 \\
\hline \multirow{4}{*}{$2 \mathrm{D}$} & Lane 1 & 0.69 & 0.34 & 0.39 & 0.36 & 0.34 \\
\hline & Lane 2 & 0.57 & 0.20 & 0.33 & 0.28 & 0.30 \\
\hline & Lane 3 & 0.34 & 0.17 & 0.24 & 0.19 & 0.16 \\
\hline & Lane 4 & 0.24 & 0.12 & 0.17 & 0.12 & 0.10 \\
\hline
\end{tabular}

\section{Conclusions}

Tests are performed on a large-scale truss girder model in this study, and the wind fields affected by a bridge tower above the bridge deck are determined in the presence of barriers with various heights, porosities, and opening forms; the conclusions obtained from the study results are given as follows:

(1) The bridge tower has a considerable impact on the wind field; with increasing height above the deck, the local wind field is primarily dominated by structures on the bridge deck and then gradually becomes affected by the tower. Barriers can reduce the sudden change in the wind speed caused by the tower and weaken the effect of the tower on the local wind field. Similar wind fields are produced for different wind barrier parameters as are obtained without towers. The influence range of the bridge tower at the windward side is twice the width of the bridge tower and somewhat larger at the leeward side.

(2) Structures on the bridge deck affect the local wind field. Structures, such as central stabilizers, increase the wind resistance of bridges but can induce a sudden change in the wind field that is detrimental to the running safety of vehicles. A design should consider the impact of structures on both wind resistance and vehicle running safety.

(3) The wind profile varies significantly with the longitudinal distance from the bridge tower. The bridge tower induces a turning point in the wind speed, which gradually moves upward going towards the lanes on the leeward side.
(4) The shadowing effect of the bridge tower and the wind barrier significantly reduces the equivalent wind speed within a four-meter height above the deck. The wind barrier weakens the sudden change in the wind speed along the bridge. The height and porosity of the wind barrier have a significantly stronger effect on the wind field than the opening type.

However, the uniform flow is used in the experiment, which is not consistent with the actual situation. Therefore, a number of high-frequency wind speed acquisition instruments are installed above the bridge to obtain the real wind data. After obtaining enough data, we will carry out the related wind tunnel test again to study the wind environment of the bridge deck under the effect of turbulence.

\section{Data Availability}

The data used to support the findings of this study are available from the corresponding author upon request.

\section{Conflicts of Interest}

The authors declare that they have no conflicts of interest.

\section{Acknowledgments}

This work was supported by the National Natural Science Foundation of China (no. 51708464), the National Key Research and Development Program of China (no. 2018YFC1507800), Primary Research \& Development Plan of Sichuan Province (no. 2019YFG0001), and the Fundamental Research Funds for the Central Universities (No. 
2682019CX02). Also, this work was supported by Doctoral Innovation Fund Program of Southwest Jiaotong University.

\section{References}

[1] A. Fenerci and O. Øiseth, "Measured buffeting response of a long-span suspension bridge compared with numerical predictions based on design wind spectra," Journal of Structural Engineering, vol. 143, no. 9, Article ID 04017131, 2017.

[2] J. Hu and R. Shen, "Technical innovations of the Aizhai bridge in China," Journal of Bridge Engineering, vol. 19, no. 9, Article ID 04014028, 2014.

[3] M. J. Post and W. D. Neff, "Doppler lidar measurements of winds in a narrow mountain valley," Bulletin of the American Meteorological Society, vol. 67, no. 3, pp. 274-281, 1986.

[4] J. Zhang, M. Zhang, Y. Li, and C. Fang, "Comparison of wind characteristics at different heights of deep-cut canyon based on field measurement," Advances in Structural Engineering, vol. 23, no. 2, pp. 219-233, 2020.

[5] L. Salati, P. Schito, and F. Cheli, "Wind tunnel experiment on a heavy truck equipped with front-rear trailer device," Journal of Wind Engineering and Industrial Aerodynamics, vol. 171, pp. 101-109, 2017.

[6] S.-J. Kim and H.-K. Kim, "Feasibility of a quasi-static approach in assessing side-wind hazards for running vehicles," Applied Sciences, vol. 9, no. 16, p. 3377, 2019.

[7] D. Rocchi, T. Argentini, and M. Sbrosi, "Pressure distribution and global forces on a bridge deck section: experimental and CFD analysis of static aerodynamic forces," Journal of Bridge Engineering, vol. 20, no. 9, Article ID 04014097, 2015.

[8] H. Kozmar, L. Procino, A. Borsani, and G. Bartoli, "Sheltering efficiency of wind barriers on bridges," Journal of Wind Engineering and Industrial Aerodynamics, vol. 107-108, no. Supplement C, pp. 274-284, 2012.

[9] H. Kozmar, L. Procino, A. Borsani, and G. Bartoli, "Optimizing height and porosity of roadway wind barriers for viaducts and bridges," Engineering Structures, vol. 81, no. Supplement C, pp. 49-61, 2014.

[10] S.-J. Lee and H.-B. Kim, "Laboratory measurements of velocity and turbulence field behind porous fences," Journal of Wind Engineering and Industrial Aerodynamics, vol. 80, no. 3, pp. 311-326, 1999.

[11] S.-J. Lee and H.-C. Lim, "A numerical study on flow around a triangular prism located behind a porous fence," Fluid Dynamics Research, vol. 28, no. 3, pp. 209-221, 2001.

[12] X. Wu, X. Zou, C. Zhang, R. Wang, J. Zhao, and J. Zhang, "The effect of wind barriers on airflow in a wind tunnel," Journal of Arid Environments, vol. 97, pp. 73-83, 2013.

[13] J. Zhang, M. Zhang, Y. Li, Y. Qian, and B. Huang, "Local wind characteristics on bridge deck of twin-box girder considering wind barriers by large-scale wind tunnel tests," Natural Hazards, vol. 102, no. 2, pp. 1-16, 2020.

[14] M. Telenta, J. Duhovnik, F. Kosel, and V. Šajn, "Numerical and experimental study of the flow through a geometrically accurate porous wind barrier model," Journal of Wind Engineering and Industrial Aerodynamics, vol. 124, pp. 99-108, 2014.

[15] M. Telenta, M. Batista, M. E. Biancolini, I. Prebil, and J. Duhovnik, "Parametric numerical study of wind barrier shelter," Wind and Structures, vol. 20, no. 1, pp. 75-93, 2015.

[16] Y. Su, H. Xiang, C. Fang, L. Wang, and Y. Li, "Wind tunnel tests on flow fields of full-scale railway wind barriers," Wind and Structures, vol. 24, no. 2, pp. 171-184, 2017.
[17] D. Wang and A. Chen, "Assessment of lateral driving stability of automobiles passing by the pylon zone under cross wind," Research Journal of Applied Sciences, Engineering and Technology, vol. 4, no. 16, pp. 2735-2739, 2012.

[18] T. Argentini, E. Ozkan, D. Rocchi, L. Rosa, and A. Zasso, "Cross-wind effects on a vehicle crossing the wake of a bridge pylon," Journal of Wind Engineering and Industrial Aerodynamics, vol. 99, no. 6-7, pp. 734-740, 2011.

[19] S. Charuvisit, K. Kimura, and Y. Fujino, "Effects of wind barrier on a vehicle passing in the wake of a bridge tower in cross wind and its response," Journal of Wind Engineering and Industrial Aerodynamics, vol. 92, no. 7-8, pp. 609-639, 2004.

[20] B. Wang and Y.-L. Xu, "Safety analysis of a road vehicle passing by a bridge tower under crosswinds," Journal of Wind Engineering and Industrial Aerodynamics, vol. 137, pp. 25-36, 2015.

[21] N. Zhang, G. Ge, H. Xia, and X. Li, "Dynamic analysis of coupled wind-train-bridge system considering tower shielding and triangular wind barriers," Wind and Structures, vol. 21, no. 3, pp. 311-329, 2015.

[22] L. Salati, P. Schito, D. Rocchi, and E. Sabbioni, "Aerodynamic study on a heavy truck passing by a bridge pylon under crosswinds using CFD," Journal of Bridge Engineering, vol. 23, no. 9, Article ID 04018065, 2018.

[23] M. Zhang, Y. Li, B. Wang, and S. Ren, "Numerical simulation of wind characteristics at bridge site considering thermal effects," Advances in Structural Engineering, vol. 21, no. 9, pp. 1313-1326, 2018.

[24] M. Zhang, J. Zhang, Y. Li, J. Yu, J. Zhang, and L. Wu, "Wind characteristics in the high-altitude difference at bridge site by wind tunnel tests," Wind and Structures, vol. 30, no. 6, pp. 547-558, 2020.

[25] M. Zhang, J. Zhang, Y. Li et al., "Multi-site measurement for energy application of small distributed wind farm in complex mountainous areas," Energy Reports, vol. 6, pp. 1043-1056, 2020.

[26] Y. Li, P. Hu, C. S. Cai, M. Zhang, and S. Qiang, "Wind tunnel study of a sudden change of train wind loads due to the wind shielding effects of bridge towers and passing trains," Journal of Engineering Mechanics, vol. 139, no. 9, pp. 1249-1259, 2013.

[27] S. Charuvisit, K. Kimura, and Y. Fujino, "Experimental and semi-analytical studies on the aerodynamic forces acting on a vehicle passing through the wake of a bridge tower in cross wind," Journal of Wind Engineering and Industrial Aerodynamics, vol. 92, no. 9, pp. 749-780, 2004.

[28] S. A. Coleman and C. J. Baker, "The reduction of accident risk for high sided road vehicles in cross winds," Journal of Wind Engineering and Industrial Aerodynamics, vol. 44, no. 1-3, pp. 2685-2695, 1992.

[29] S.-J. Kim, C.-H. Yoo, and H.-K. Kim, "Vulnerability assessment for the hazards of crosswinds when vehicles cross a bridge deck," Journal of Wind Engineering and Industrial Aerodynamics, vol. 156, pp. 62-71, 2016.

[30] J. Zhang, M. Zhang, Y. Li, X. Huang, and Z. Zheng, "Aerodynamics of high-sided vehicles on truss girder considering sheltering effect by wind tunnel tests," The Baltic Journal of Road and Bridge Engineering, vol. 15, no. 2, pp. 66-88, 2020. 